\title{
GC/MS analysis and In-vitro Antioxidant activity of methanol extract of Ulothrix flacca and its main constituent Dimethyl Sulfone.
}

\author{
B. Vasudevarao ${ }^{1}$, D.J. Sravanthi ${ }^{2}$ \\ ${ }^{I}$ (Research Scholar, Bharathidasan University, Trichy, 620024, Tamilnadu, India.) \\ ${ }^{2}$ (Assistant Professor, Department of Pharmaceutical Analysis, M.R.R College of Pharmacy (JNT University \\ Kakinada), 521366, Andhra Pradesh, India.)
}

\begin{abstract}
The determination of phytochemical constituents, total phenol, flavonoid contents and antioxidant assays of methanol extract of Ulothrix flacca and its main constituent dimethyl sulfone was studied. The mass spectra of the compounds were matched with the NIST library. The GC-MS analysis of methanol extracts of Ulothrix flacca showed sixteen peaks. Of all the sixteen chemical compounds revealed from the GC-MS analysis of Ulothrix flacca, Dimethyl Sulfone (C2H6O2S) (RT-8.9), 4-Bromobenzoic Acid, 2-Chlorophenyl Ester (Cl3H8BrClO2) (RT-12.642), Tetradecanoic Acid, 10,13-Dimethyl-, Methyl Ester (C17H34O2) (RT-18.669) are the three major components. The methanol extracts of Ulothrix flacca possess phenolic and flavonoid content of $(5.74 \pm 0.45 \mathrm{mg}$ Gallic acid equivalent $(G A E) / g$ Wt, and $12.58 \pm 1.52 \mathrm{mg}$ quercetin eq/g wt) respectively. Antioxidant activity was determined using 1,1-diphenyl-2-picryl hydrazyl (DPPH) free radical, for evaluating free radicle scavenging activity, ABTS radical cation scavenging activity, Ferric reducing antioxidant power (FRAP) assay, Phosphomolybdenum assay and Metal chelating activity using BHT, Rutin and Quercetin. The highest radicle scavenging activity was shown by dimethyl sulfone $(15.156 \mathrm{mg} / \mathrm{ml})$, which is higher than the BHT and Rutin. In vitro antioxidant activity of methanolic extract of Ulothrix flacca and Dimethyl sulfone showed an increase with increasing concentration indicating positive association with the total phenolic and flavonoid contents of the extract, which could be considered for future applications in medicine, dietary supplements, cosmetics or food industries.
\end{abstract}

Keywords: GC-MS analysis, Antioxidant assays, Ulothrixflacca, Dimethyl Sulfone.

\section{Introduction}

Ulothrix flacca belongs to the family Ulothricaceae. The thallus is with unbranched filaments having single line of cells (uniseriate) to $5-7 \mathrm{~cm}(2.5 \mathrm{inch})$ in length. The filaments generally forms in a thick mass and appear dark green on the rocks. The cells possess a single nucleus, and although narrow (15-35 m diameter), they are shorter $(6-16 \mathrm{~m}$ long) than wide. The complete length of the cell is filled with collar shaped chloroplast. Reproductive cells appear swollenin the middle to $50 \mu \mathrm{m}$ in diameter[1]. These species forms a very slippery coating on rocks in the mid to high intertidal zone in protected to semi-exposed areas in early summer.

During normal metabolism and energy production in the body, Oxygen derived free radicals or reactive oxygen species (ROS) as well as reactive nitrogen species (RNS) includingsuperoxide $\left(\mathrm{O}_{2}\right)$, hypochlorous acid $(\mathrm{HOCl})$, hydroxyl (.OH), nitrous acid $\left(\mathrm{HNO}_{2}\right)$, Peroxyl (ROO.), hydrogen peroxide $\left(\mathrm{H}_{2} \mathrm{O}_{2}\right)$, nitroxide (NO.), peroxy nitrite (OONO.) and dinitrogen trioxide $\left(\mathrm{N}_{2} \mathrm{O}_{3}\right)$ are generated[2]. Their production helps the normal healthy tissues perform physiological roles such as molecular signalling, signal transduction regulation, gene expression, activation of receptor mechanism and nuclear transduction among others[3]. When these ROS or RNS are in higher concentrations beyond the actual antioxidant capacity of a biological system, due to some metabolic and other environmental factors; such condition gives rise to an imbalance state known as oxidative or nitrosative stress; a situation that mediates damage to the biological molecules such as proteins, lipids, DNA and polysaccharides[3]. In the past decade, free radicles were implicated by showing the relevance of antioxidants in preventing various diseases[4]. The presence of antioxidants like flavonoids, phenolics, proanthocyanidins and tannins in plants and seaweeds may provide protection against a number of diseases; for example, the mortality from degenerative disorders has been inversely proportional to the ingestion of natural antioxidants [5].

Seaweeds are therefore being investigated for their antioxidant properties, and the demand for such natural antioxidants and food preservatives is increasing [6]. The oxidation processes of all living organisms are very intrinsic in the energy management, and are, therefore, should be kept under strict control by several cellular mechanisms [7]. Several types of extracts obtained from seaweeds have received special attention due to their potent pharmaceutical activities, including anticancer, immune-stimulant and antioxidant activities [8]. Seaweeds contain high amounts of polyphenols. For example, in the seaweed Halimada (Chlorophyceae), high 
concentrations of polyphenols such as epicatechin, catechin, gallate, gallic acid and epigalloctechin are reported [9]. Algae generally has higher antioxidant activity due to a higher contents of nonenzymatic antioxidant components, such as ascorbic acid, phenols, reduced glutathione and flavonoids [10].

Dose dependent alterations were observed in Total Antioxidant Capacity, Total Oxidative stress levels and Nuclear Divison Index rates of Ulothrixtenuissima (Kurtz.). It was found to be non-genotoxic and caused sterility at higher concentrations due to oxidative stress [11]. However, in this seaweed, till date there are no detailed studies concerning the active components reported.Therefore,by using Gas Chromatography-Mass Spectrometry (GCMS) analysis, the present study was conducted to analyze the phytochemicals of unexplored seaweed, Ulothrix flacca. Thus the present study aimed to determine the Antioxidant potential with determination of its total phenolic and flavonoid contents, and GCMS analysis was performed for the identification of the phytochemical constituents.

\subsection{Chemicals and Reagents}

\section{Materials And Methods}

All the analytical grade solvents and chemicals were obtained from Himedia chemicals, Mumbai, India. 2, 2 - azinobis 3-ethylbenzothiozolin-6-sulphonate (ABTS) was obtained from Sigma chemicals, USA. The other chemicals used were Gallic acid, quercetin, Rutin, 2,2- diphenylpicryl-1-picrylhydrazyl (DPPH), Butylated hydroxytoluene (BHT), Ethylene diamine tetra acetic acid (EDTA), Trolox, Potassium persulphate.

\subsection{Seaweed Collection}

Ulothrix flacca is the green seeweed collected during the months of July and August, from the rocky platforms at Tenneti Park located at Vishakhapatnam coastal banks, Andhra Pradesh, India. Species identification was done by referring the printed journal (Y. Sarojini, P. Santharao, B. Sujatha K. Lakshminarayana. Distribution and diversity of marine macro algae in relation to environmental factors at Visakhapatnam coast. Seaweed Res. Utiln., 35 (1\&2): 55-64, 2013 and authentified at Department of Botany, Andhra University, Visakhapatnam.

\subsection{Methanol Extract Preparation}

Seaweed sample was cleaned of epiphytes and extraneous matter, and necrotic parts were removed. Seaweeds were washed with seawater and then in fresh water. The seaweed was transported to the laboratory in sterile polythene bags at $0^{\circ} \mathrm{C}$ temperature. In the laboratory, sample was rinsed with sterile distilled water and were shade dried, cut into small pieces and powdered in a mixer grinder. The powdered sample was extracted in methanol thrice by soaking for overnight at room temperature. The extract from three consecutive soakings was pooled and evaporated under reduced pressure. The residue (crude extract) obtained was finally dried under vacuum pressure.

\subsection{GC-MS Analysis}

The seaweed Ulothrix flaccawas subjected to GC-MS analysis for its structural characterization. GC-MS analysis was carried out using Clarus 600 gas chromatograph system. It is equipped with Claru600C mass spectrometer (PerkinElmer, USA). For GC-MS, an Elite-5MS fused silica capillary column coated with a 5\% diphenyl/95\% dimethyl polysiloxane stationary phase $(60 \mathrm{~m} \times 0.25 \mathrm{~mm}$, film thickness $0.10 \mathrm{~m}$; PerkinElmer precisely, USA) was used. For a total run time of $30 \mathrm{~min}$, the injector temperature was kept at $200{ }^{\circ} \mathrm{C}$ whereas the oven temperature was programmed from $70{ }^{\circ} \mathrm{C}$ to $300{ }^{\circ} \mathrm{C}$. Helium was used as carrier gas at a flow rate of 1 $\mathrm{mL} / \mathrm{min}$. An appropriate blank was run from which the solvent delay was fixed to $4 \mathrm{~min}$. The electron ionization mode with ion source temperature of $200{ }^{\circ} \mathrm{C}$; ionization energy of $70 \mathrm{eV}$; scan interval of $0.2 \mathrm{~s}$, GC interface temperature of $240{ }^{\circ} \mathrm{C}$ and fragments range from 50 to $600 \mathrm{~m} / \mathrm{z}$ were set for the MS analysis. About $1 \mu \mathrm{L}$ of the extract was injected manually in a split less mode.

\subsection{Identification of Phytoconstituents}

Using the database of National Institute Standard and Technology (NIST) having huge data with their fragmentation pattern, Interpretation on Mass-Spectrum of GC-MS was conducted. The spectrum of known components stored in the NIST library was used to compare the spectrum and fragmentation pattern of the unknown compounds. The name, structure and molecular weight of the components of the test materials were determined.

\subsection{Determination of Total Phenolic Content}

The level of total phenols in the crude extract of Ulothrix flaccawas determined by using FolinCiocalteu reagent and external calibration with gallic acid. In this method $200 \mu \mathrm{L}$ of seaweed extract was taken into a series of test tubes and made up to $1 \mathrm{~mL}$ with distilled water. Then, $500 \mu \mathrm{L}$ of Folin - Ciocalteau Phenol reagent $(1 \mathrm{~N})$ was added to all the test tubes including the blank and mixed thoroughly [12]. After 5 minutes, 2.5 
$\mathrm{mL}$ of sodium carbonate solution $(5 \%)$ was added to all the test tubes. All the test tubes were vortexed well to mix the contents and incubated in dark for 40 minutes. The formation of blue color in the incubated test tubes indicated the presence of phenolics. After incubation the absorbance was read at $725 \mathrm{~nm}$ against the reagent blank (distilled water) using spectrophotometer (Thermo Fisher Scientific, model 4001/4). The concentration of the total phenolics was calculated as $\mathrm{mg}$ of gallic acid equivalent by using an equation obtained from gallic acid calibration curve and the results were expressed as Gallic acid equivalents (GAE). The determination of total phenolic compounds in the fractions was carried out in triplicate and the results were averaged.

\subsection{Determination of Total Flavonoid Content}

Total flavonoid contents of Ulothrixflaccawas determined according to the method described by Zhishenet al.,[13]. About $500 \mu \mathrm{L}$ of seaweed extract was taken in series of test tubes and $2 \mathrm{~mL}$ of distilled water was added to each test tube. Then, $150 \mu \mathrm{L}$ of $5 \% \mathrm{NaNO}_{2}$ was added to all the test tubes followed by incubation at room temperature for 6 min. After incubation, $150 \mu \mathrm{L}$ of $10 \% \mathrm{AlCl}_{3}$ was added to all the test tubes including the blank. All the test tubes were incubated for 6 minutes at room temperature. Then $2 \mathrm{~mL}$ of $4 \% \mathrm{NaOH}$ was added to all the test tubes and were made up to $5 \mathrm{~mL}$ using distilled water. After vortexing the contents in all the test tubes, they were allowed to stand for 15 minutes at room temperature. The development of pink color due to the presence of flavonoids was read spectrophotometrically at $510 \mathrm{~nm}$ against blank (distilled water). The total flavonoid compounds determination in the fractions was carried out in triplicate and the results were averaged. The results were expressed in Rutin equivalents (RE).

\subsection{DPPH Radical Scavenging Activity}

According to the method described by Bracaet al., the antioxidant activity of the extract was determined in terms of hydrogen donating or radical scavenging ability using the stable radical DPPH[14]. Seaweed Sample and Dimethyl sulfone were taken with varying concentrations and the volume was adjusted to

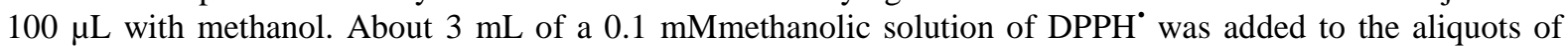
samples and standards (BHT and Rutin) was vortexed well. Negative control was prepared by adding $100 \mu \mathrm{L}$ of methanol in $3 \mathrm{~mL}$ of $0.1 \mathrm{mMmethanolic}$ solution $\mathrm{DPPH}^{\circ}$. The tubes were allowed to stand in dark for 15 minutes at room temperature. The absorbance of the samples were measured at $517 \mathrm{~nm}$ against the blank. Radical scavenging activity of the samples were expressed as $\mathrm{IC}_{50}$ which is the concentration of the sample required to inhibit $50 \%$ of $\mathrm{DPPH}^{*}$ concentration. The antioxidant capacity was calculated using the following equation:

$\%$ Inhibition $=\left(\mathrm{A}_{\text {cotrol }}-\left(\mathrm{A}_{\text {sample }}-\mathrm{A}_{\text {blank }}\right) / \mathrm{A}_{\text {cotrol }}\right) \times 100$

Where the $\mathrm{A}_{\text {sample }}$ is the absorbance of the test sample (the sample test and DPPH solution), $\mathrm{A}_{\text {cotrol }}$ is the absorbance of the control (DPPH without sample), and the $A_{\text {blank }}$ is the absorbance of the sample blank (Sample without the DPPH solution). Ascorbic acid was used as the positive control. The $\mathrm{IC}_{50}$ values were calculated by linear regression analysis and expressed as mean of three determinations.

\subsection{ABTS Radical Cation Scavenging Activity}

The total antioxidant activity of the samples were measured by ABTS radical cation decolourization assay according to the method described by Re et al., [15]. 2,2-azinobis-(3-ethylbenzothiazoline-6-sulfonic acid) $\mathrm{ABTS}^{\circ+}$ was produced upon the reaction of $7 \mathrm{mM}$ ABTS aqueous solution with $2.4 \mathrm{mM}$ potassium persulfate in the dark for 12-16 hours at room temperature. Prior to assay, this solution was diluted with methanol (about $1: 89 \mathrm{v} / \mathrm{v}$ ) and equilibrated at $30^{\circ} \mathrm{C}$ to produce an absorbance of $0.700 \pm 0.02$ at $734 \mathrm{~nm}$. After the addition of $1 \mathrm{~mL}$ of diluted $\mathrm{ABTS}^{\circ+}$ solution to $10 \mu \mathrm{L}$ of the seaweed extract and Dimethyl sulfone all the test tubes were vortexed well and incubated in dark for $30 \mathrm{~min}$ at room temperature. Triplicate determinations were made at each dilution of the standards (BHT and Rutin), seaweed extract and Dimethyl sulfone and the absorbance was read against the blank at $734 \mathrm{~nm}$. The unit of total antioxidant activity (TAA) is defined as the concentration of Trolox having equivalent antioxidant activity expressed as $\mu \mathrm{M} \mathrm{TE} / \mathrm{g}$ of seaweed extract.

\subsection{Ferric Reducing Antioxidant Power (FRAP) Assay}

The antioxidant capacities of samples were estimated according to the procedure described by Pulido et al. [16]. FRAP reagent $(900 \mu \mathrm{L})$, prepared freshly and incubated at $37^{\circ} \mathrm{C}$ for $30 \mathrm{~min}$, was mixed with $90 \mu \mathrm{L}$ of distilled water and $30 \mu \mathrm{L}$ of test samples or blank. The test samples and reagent blank were incubated at $37^{\circ} \mathrm{C}$ for 30 minutes in a water bath. The final dilution of the test samples in the reaction mixtures was $1 / 34$. The FRAP reagent was prepared by mixing $2.5 \mathrm{~mL}$ of $20 \mathrm{mM} \mathrm{FeCl}_{3} .6 \mathrm{H}_{2} \mathrm{O}, 2.5 \mathrm{~mL}$ of $20 \mathrm{mM}$ 2,4,6-Tris(2-pyridyl)s-triazine (TPTZ) in $40 \mathrm{mMHCl}$ and $25 \mathrm{~mL}$ of $0.3 \mathrm{M}$ acetate buffer (pH-3.6). At the end of incubation, the absorbance readings were taken immediately at $593 \mathrm{~nm}$ against the reagent blank, using a spectrophotometer. Methanolic solutions of known Fe (II) concentration, ranging from 100 to $2000 \mu \mathrm{M},\left(\mathrm{FeSO}_{4} .7 \mathrm{H}_{2} \mathrm{O}\right)$ were used for the preparation of the calibration curve. Equivalent Concentration (EC) was defined as the concentration of antioxidant having a ferric-Tris(2-pyridyl)-s-triazine reducing ability equivalent to that of $1 \mathrm{mM} \mathrm{FeSO}_{4} \cdot 7 \mathrm{H}_{2} \mathrm{O}_{\text {. }}$ 
EC was calculated as the concentration of the antioxidant giving an absorbance increase in the FRAP assay equivalent to that of the theoretical absorbance value of a $1 \mathrm{mM}$ concentration of Fe (II) solution. Rutin and Quercetin were used as standards.

\subsection{Phosphomolybdenum Assay}

The antioxidant activities of extracts were evaluated by the formation of green phosphomolybdenum complex, according to the method of Prieto et al. [17]. About $100 \mu \mathrm{L}$ aliquots of the seaweed extract and dimethyl sulfone were added with $3 \mathrm{~mL}$ of reagent solution $(0.6 \mathrm{M}$ sulphuric acid, $28 \mathrm{mM}$ sodium phosphate and $4 \mathrm{mM}$ ammonium molybdate). The test tubes were covered with foil and then incubated in a water bath at $95^{\circ} \mathrm{C}$ for 90 minutes. The absorbance of the mixtures were measured at $695 \mathrm{~nm}$ against the reagent blank, after the samples had cooled to room temperature. The results were reported by means of mean value expressed as mg AAE /g extract. Rutin and Quercetin were used as reference standards.

\subsection{Metal Chelating Activity}

The ability of Ulothrix flacca seaweed extract and Dimethyl sulfone to chelate the ferrous ions were estimated by the method described by Dinis et al., [18] with slight modifications. Initially, about $50 \mu \mathrm{L}$ of the extracts and BHT (Butylated hydroxyl toluene) were added to $100 \mu \mathrm{L}$ solution of $2 \mathrm{mM} \mathrm{FeCl}_{2}$. The reaction was initiated by the addition of $400 \mu \mathrm{L}$ of $5 \mathrm{mMferrozine}$ and the mixtures were made up to $3 \mathrm{~mL}$ using deionized water. The contents were shaken vigorously and left at room temperature for 10 minutes. Absorbance of the solutions were then measured spectrophotometrically at $562 \mathrm{~nm}$ against the blank. The percentage inhibition of ferrozine-Fe 2+ complex formation was calculated as $[(\mathrm{A} 0-\mathrm{As}) / \mathrm{As}] \times 100$, where As was the absorbance of the extract/ standard and $\mathrm{A} 0$ was the absorbance of the control. $\mathrm{Na}_{2}$ EDTA was used as positive control. EDTA was used as the standard metal chelating agent and the results were expressed in mg EDTA equivalents/g extract.

\section{Statistical Analyses}

The experimental results were mean \pm S.D. of three measurements and analyzed by SPSS 10 (SPSS Inc. Chicago, IL). Correlations were obtained by the Pearson correlation coefficient in bivariate correlations and $P$ values $<0.05$ were regarded as significant.

\section{Results \\ 3.1 GC-MS analysis of Ulothrix flacca methanol extract}

Gas Chromatography Mass Spectroscopy (GC-MS) was performed to identify the active constituents from the seaweed extract. The compounds identified are listed in Table 1.

Totally sixteen compounds were identified in methanolic extract of Ulothrix flaccaextract by GC-MS analysis. The chromatogram is obtained by methanolic fraction of Ulothrix flacca. Name of the natural compound, retention time, molecular formula and molecular weight and area percentage were presented in table 7. The prevailing compounds were Dimethyl Sulfone, Phenol, 2-Nitro-, Benzaldehyde, 3-Bromo-, 4Bromobenzoic Acid, 2-Chlorophenyl Ester, Benzoic Acid, 3-Bromo-, 2-Bromoethyl Ester, 3-Buten-2-One, 4-(2Bromophenyl)-, Tetradecanoic Acid, Tetradecanoic Acid, 10,13-Dimethyl-, Methyl Ester, Hentriacontane, Methanone, (4-Aminophenyl)(4-Bromophenyl)-, 2,5-Cyclohexadiene-1,4-Dione, 2,5-Diphenyl, Naphthalene, 2Phenyl-, 2-Bromobenzoic Acid, 2,4,5-Trichlorophenyl Ester, Coumarin, 4-[1-(4-Nitrophenyl)-3-Oxopentylthio], Ergotaman-3',6',18-Trione, 9,10-Dihydro-12'-Hydroxy-2'-Methyl-5'-(Phenylmethyl, Acethydrazide, 2,2,2Trifluoro-N2-(4-Bromobenzoyl)-.

The molecular structures, nature and phytochemical activities of these compounds are tabulated in the Table 8. The GC-MS spectrum of Ulothrix flaccamethanol extract is shown in the fig 1.

\subsection{Total phenolic content}

The total phenolic content of Ulothrix flacca extractwas determined by Folin-Ciocalteu method are reported as Gallic acid equivalents (Table 3). Ulothrix flacca methanol extract was containing 5.74\% amount of phenolic compounds. The content of total phenolic was carried out based on the absorbance values of the various extract solutions, reacted with Folin-Ciocalteu reagent and compared with the standard solutions of Gallic equivalents as described above.

\subsection{Total flavonoid content}

The total flavonoid contents of Ulothrix flacca extractwas determined by aluminium chloride colorimetric method are reported as quercetin equivalents. Ulothrix flacca methanol extract was containing $12.58 \%$ amount of flavonoid compounds (Table 3).

\subsection{DPPH scavenging activity}


The ability of the sample to stabilize the DPPH radical by donating the electron, for this study a relatively unstable free radical, DPPH (1, 1-diphenyl, 2-picryl hydrazyl) was selected for the invitro assay method. DPPH was used as a substrate to evaluate the antioxidant activity of natural products from plants and microbial sources. The results were depicted in Fig 1.

From the figure 1, it was evident that DPPH scavenging activity was increased with increase in concentration of the extract. The $50 \%$ scavenging ability of the extract Ulothrixflaccaand dimethyl sulfone were found to be at $9 \mu \mathrm{g} / \mathrm{mL}$ and $15 \mu \mathrm{g} / \mathrm{mL}$ respectively. And it was found that Ulothrix flacca is having comparatively equal inhibitory concentrations exerted by standard Rutin (Table 4).

\subsection{ABTS assay}

The ABTS assay is based on the inhibition of absorbance of the radical cation $\mathrm{ABTS}^{+}$, that has a long characteristic wavelength absorption spectrum. The efficiency of ABTS radical scavenging potential of Ulothrix flacca seaweed extract and Dimethyl sulfone were estimated to identify the total reducing potential and were found to be $10905.6 \pm 159.73 \mu \mathrm{M} \mathrm{TE} / \mathrm{g}$ of extract and $12755.3 \pm 185.52 \mu \mathrm{M} \mathrm{TE} / \mathrm{g}$ respectively and ABTS radical scavenging potential of Ulothrix flacca seaweed extract was found to be almost similar to the reducing potential of the natural antioxidant BHT and greater than that of Rutin. The ability of reducing capacity by standard, Dimethyl sulfone as well as the seaweed extract are described in the Table 4.

\subsection{Ferric reducing antioxidant power assay (FRAP)}

The ferric reducing ability of Ulothrix flacca seaweed extract and Dimethyl sulfone were estimated based on their ability to reduce TPTZ-Fe (III) complex to TPTZ- Fe (II). The reducing ability of the methanolic extract ofUlothrix flaccaand Dimethyl sulfone by quenching the ions were compared with Rutin and Quercetin standards and the potentials were found to be $11.577 \pm 1.131 \mathrm{mM} \mathrm{Fe}(\mathrm{II}) \mathrm{E} / \mathrm{mg}$ extract and $18.157 \pm 1.056 \mathrm{mM}$ $\mathrm{Fe}(\mathrm{II}) \mathrm{E} / \mathrm{mg}$ respectively. And the concentrations of antioxidant in the samples are given in the Table 4.

\subsection{Phosphomolybdenum assay}

The Phosphomolybdenum reduction potential (PMRP) of the seaweed extract refers to the ability of the extract to reduce phosphomolybdenum VI to phosphomolybdenum V, this reduction in turn reflects the reducing capacity of the methanol extract of Ulothrix flaccaand Dimethyl sulfone. Among the varying concentrations of the seaweed extract Ulothrix flacca(60.66mg AAE/g extract) and Dimethyl sulfone(71.45 $\pm 2.25 \mathrm{mg}$ AAE/g), Dimethyl sulfone showed better reduction potential. Which were comparable with the value of natural antioxidants Rutin and Quercetin. Thus, the total antioxidant capacity observed for the extract of Ulothrix flaccaand Dimethyl sulfone were correlated with its free radical scavenging activity equivalent to that of natural antioxidant ascorbic acid. The reducing potential of the samples were represented in the Table 4.

\subsection{Metal chelating activity}

The chelating effect on the ferrous ions by the methanol extract of seaweedUlothrix flaccaand Dimethyl sulfone were found to be $13.55 \mathrm{mg}$ EDTA/g of extract and $11.155 \pm 0.114 \mathrm{mg}$ EDTA/gm respectively. The chelating activities of samples were represented in Table 4.

\section{Discussion}

Dimethyl sulfone or Methylsulfonylmethane (MSM) is the major component identified under the GCMS analysis of Ulothrix flacca. It is an organic sulfur-containing natural compound having no reported toxicity. Dimethyl sulfone contains only eleven atoms and is found in foods, including fruits, vegetables, grains, and beverages [19]. It is a symmetric molecule with no isomeric forms. Dimethyl sulfone has also been detected in the human brain [20], blood plasma, and cerebrospinal fluid [21] by proton magnetic resonance spectroscopy. Dimethyl sulfone is volatile, easily lost during cooking, and is believed to be non-toxic [22], [23]. Dimethyl sulfone decreases arthritis pain and improves physical function of osteoarthritis human knees without major adverse events [24]. This compound has also been found to be effective for treating allergies [25], osteoarthritis pain [26], inflammation [27], repetitive stress injuries [28], and bladder disorders like intestinal cystitis [29]. Dimethyl sulfone can induce wound healing, contact inhibition, and can block the ability of cells to migrate through the extra-cellular matrix. Furthermore, in arbors seen in murine melanoma cell lines, Dimethyl sulfone can restore anchorage-dependent growth and irreversible senescence followed by arborization with melanosomes[30]. It inhibited the proliferation of HER2-positive and estrogen receptor-positive breast cancer cells in a dose-dependent manner [31].

2-Nitrophenol is a water soluble, yellow, crystalline material, moderately toxic, low melting point $\left(45^{\circ}\right.$ C). When heated to decomposition 2-Nitrophenol emits toxic fumes of oxides of nitrogen. In molten form violent reaction with strong alkali $(85 \%$ potassium hydroxide). Thesenitrophenols are blood poisons, but they alsoact onthenervoussystem andirritate theskin and 
mucousmembranes, leading to dermatitis and chronic eczema.Themain use ofortho-andparanitrophenolsis in the production of ortho- and para-aminophenols. The permeation of nitrophenols through epidermal cells was studied from newborn rat skin cultured on type IV collagen-coated Millipore filters with positive results[32].

Acethydrazide, 2,2,2-Trifluoro-N2-(4-Bromobenzoyl)- is the chemical component that has been showed up in the seaweed extract. Relative compounds are having Antituberculosis and antiinflammatory activities. Alpha-[5-(5-Nitro-2-furyl)-1,3,4-oxadiazol-2-ylthio]acethydrazide, alpha-[5-(5-nitro-2-furyl)-1,3,4oxadiazol-2 ylthio]acetamide, delta-allyl-1-[( 5-(5-nitro-2-furyl)-1,3,4-oxadiazol-2-ylthio]acety) thiosemicarbazide, and other related compounds weresynthesised for testing against Mycobacterium tuberculosis [33]. 2-Methylindole-3-acethydrazide was reacted with arylisothiocyanate to give the corresponding 4-arylthiosemicarbazides $2 \mathrm{a}-\mathrm{d}$.

Ergotaman-3',6',18- Trione, 9,10- Dihydro-12'- Hydroxy-2'- Methyl-5' (Phenylmethyl), is the chemical compound that was identified in the GC-MS analysis of Ulothrix flacca. Ergotamine damages the peripheral epithelium as well as produces vasoconstriction peripherally. Ergotamine is conducive to vascular stasis, thrombosis, and gangrene in high doses. It can be used to increase uterine contractivity and occasionally as a post-partum to decrease uterine bleeding. Ergotamine continues to be prescribed for migraines. The common name of prescription is Cafergot which is a combination of caffeine and ergotamine. Contraindications include Raynaud's Syndrome, Coronary Artery Disease, Pregnancy, Pruritus, Hepatic disease, Atherosclerosis, Buerger's syndromeand Renal Disease [34].

Tetradecanoic Acid, 10,13-Dimethyl-, Methyl Ester is the compound that was identified in Ulothrix flacca.Tetradecanoic acid or Myristic acid (14 carbon atoms) was discovered in the seed of the tropical tree Myristicafragrans, from which its name.It is a saturated fatty acid member of the sub-group called long chain fatty acids (LCFA), from 14 to 18 carbon atoms. It occurs, as glycerol ester, in most animal and vegetable fats and oils. Tetradecanoic acid presence was registered from seven different types of date fruits when investigating their Physical and chemical properties, antioxidant activity, total phenol and mineral profile [35]. The fatty acid composition of date seed oil revealed the presence of five dominant fatty acids, where Myristic acid is one of them [36]. Myristic acid is used as a surfactant, cleansing, opacifying\& thickening agent in cosmetics products. Has also emulsifying properties. Mostly all kinds of personal care products including soaps, cleansing creams, lotions, hair conditioners, shaving products contains myristic acid [37].

Coumarin, 4-[1-(4-Nitrophenyl)-3-Oxopentylthio] - is the compound that was identified in Ulothrix flacca. Natural coumarins comprise five major subtypes-simple coumarins, linear furanocoumarins, angular furanocoumarins, linear pyranocoumarins, and angular pyranocoumarins. Several natural coumarins exhibit strong antifungal activities and can be examined as potential lead compounds for developing novel antifungal agents [38]. Synthesized coumarin derivatives showed significant anti-inflammatory and anticancer activity, which can be regarded as the promising drug candidates for development of anticancer drugs targeting cancerrelated inflammation (Thomas et. al., 2016). According to Singhla and Piplani (2016)[39], a synthesized coumarin related compound displayed significant antiamnesic activity, antioxidant activity in comparison to donepezil and AChE inhibitory activity.

The key role of phenolic and flavonoid compounds in free radical scavenging and/or reducing systems was supported by the data obtained from the total phenolic and flavonoid methods. The way of determination of the level of total phenolics is based on the compounds chemical reducing capacity relative to Gallic acid but not based on absolute measurements of the amounts of phenolic compounds. It is important to note that; there is a positive relationship between antioxidant activity and the amount of phenolic compounds of the crude extracts. The phenolic derivative compounds tend to be the vital antioxidants which are responsible to exhibit scavenging efficiency on the free radicals. Reactive oxygen species are numerous and widely distributed in the plant kingdom [40]. Total phenolic and flavonoid contents of the chlorophyceae memberUlothrixflacca showed positive correlations with the DPPH radical scavenging activity. The extract of Ulothrix flaccawas found to be the less potent scavenger in the tested samples. The DPPH antioxidant assay is based on the ability of 1, 1diphenyl-2-picrylhydrazyl (DPPH), a stable free radical, to decolorize in the presence of antioxidants [41]. Ascorbic acid was usedas the reference antioxidant in this test. The DPPH radical contains an odd electron, which is responsible for the absorbance at 515-517 $\mathrm{nm}$ and also for a deep purple color. The DPPH is decolorized when DPPH accepts an electron donated by an antioxidant compound, which can be quantitatively measured from the changes in absorbance. The IC50 values of all the samples have been furnished in the Table 4. Scavenging of DPPH radical was found to rise with increasing concentration of the samples. The redox properties of the phenolic compounds are responsible for the antioxidant activity, which plays an important role in adsorbing and neutralizing the free radicals, quenching singlet and triplet oxygen, or decomposing peroxides [42].

ABTS is a decolorization assay applicable to both lipophilic and hydrophilic antioxidants, including flavonoids, hydroxycinnamates, carotenoids and plasma antioxidants. The radical monocation of ABTS [2,2- 
azinobis-(3-ethylbenzothiazoline-6-sulfonic acid)] is generated by the oxidation of ABTS with potassium persulfate and is reduced in the presence of hydrogen-donating antioxidants. Both the duration of reaction and concentration of antioxidant on the inhibition of the radical cation absorption are taken into consideration when determining the antioxidant activity. This assay improves the original TEAC assay (the ferryl myoglobin/ABTS assay) for determining the antioxidant activity in two ways. First, the chemistry of direct generation of the ABTS radical monocation without the involvement of an intermediary radical. Second, is a decolorization assay; rather than the generation of the radical taking place continually in the presence of the antioxidant, the radical cation is formed prior to addition of antioxidant test systems. In the present study Dimethyl sulfonewas found to have the highest total reducing capacity than the Ulothrix flacca extract.

Ferric reducing antioxidant power (FRAP) table 4, shows the reducing power capabilities of the samples compared to ascorbic acid. The samples displayed good reducing power which was found to rise with increasing concentrations of the samples. In reducing power assays, the presence of antioxidants in the samples can reduce the oxidized form of iron $(\mathrm{Fe} 3+)$ to its reduced form $(\mathrm{Fe} 2+)$ by donating an electron. So it can be assumed that the presence of reductants (antioxidants) in the chlorophyceae extract and Dimethyl sulfone causes the reduction of the Fe3+/ferricyanide complex to the ferrous form. Therefore, the Fe2+ complex can be measured by the formation of Perl's Prussian blue at $700 \mathrm{~nm}$. A higher absorbance indicates greater reducing power ability [43]. Significantly Dimethyl sulfone showed better reducing capacity than the Ulothrix flaccamethanol extract.

The total antioxidant capacity (TAC) depends on the reduction of Mo(VI) to Mo(V) by the sample and subsequent formation of green phosphate/Mo(V) complex at acid $\mathrm{pH}$. It can evaluate both water-soluble and fatsoluble antioxidants. It was observed that the Dimethyl sulfone possesses significant total antioxidant capacity when compared to the seaweed extract and lesser activity to the standards Rutin and Quercetin (table 4).

The chelating of $\mathrm{Fe}^{2+}$ by extract was estimated by the method of Dinis et al. (1994). Transition metal ions in biological system could catalyse the Haber-Weiss and Fentontype reactions, resulting in the generation of hydroxyl radicals $\left(\mathrm{OH}^{*}\right)$. These transition metal ions could form chelate with the antioxidants, which result in the suppression of $\mathrm{OH}^{*}$ generation, and inhibit the peroxidation process of biological molecules. Ferrozine can quantitatively form complexes with $\mathrm{Fe}^{2+}$. However, in the presence of chelating agents, the complex formation is disrupted with the result that the red colour of the complex is decreased. Measurement of colour reduction allows the estimation of the chelating activity of the coexisting chelator. $\mathrm{Fe}^{2+}$, the transition metal ion possess the ability to move single electrons which can form and propagate many radical reactions, even starting with relatively non-reactive radicals ${ }^{[44]}$. Dimethyl sulfone, the most active sample followed by Ulothrix flacca extract interfered with the formation of ferrous and ferrozine complex, suggesting that it has chelating activity and captures ferrous ion before ferrozine. The chelating effect of other extracts on $\mathrm{Fe}^{2+}$ and ferrozine complex formation is shown in Table 4.

\section{Figures And Tables}

TABLE 1:The active compounds in Ulothrix flacca methanol extract analyzed by GC-MS analysis

\begin{tabular}{|c|c|c|c|c|c|}
\hline PEAK & RTIME & NAME OF THE COMPOUND & $\begin{array}{l}\text { MOLECULAR } \\
\text { FORMULA }\end{array}$ & $\begin{array}{l}\text { MOLECULAR } \\
\text { WEIGHT }\end{array}$ & AREA \% \\
\hline 1 & 8.9 & Dimethyl Sulfoue & $\mathrm{C}_{2} \mathrm{H}_{2} \mathrm{O}_{2} \mathrm{~S}$ & 94 & 23.46 \\
\hline 2 & 10.626 & Phenol, 2-Nitro- & $\mathrm{C}_{4} \mathrm{H}_{3} \mathrm{NO}_{3}$ & 139 & 9.59 \\
\hline 3 & 11.541 & Benzaldebyde, 3-Bromo- & $\mathrm{C}_{-} \mathrm{H}_{3} \mathrm{BrO}$ & 184 & 0.1 \\
\hline 4 & 12.642 & $\begin{array}{l}\text { 4-Bromobenzoic Acid, 2-Chlorophenyl } \\
\text { Ester }\end{array}$ & $\mathrm{C}_{13} \mathrm{H}_{4} \mathrm{BrClO}_{2}$ & 310 & 16.41 \\
\hline 5 & 14002 & $\begin{array}{l}\text { Benzoic Acid, 3-Bromo-, 2-Bromoethyl } \\
\text { Ester }\end{array}$ & $\mathrm{C}_{4} \mathrm{H}_{3} \mathrm{Br}_{2} \mathrm{O}_{2}$ & 306 & 0.36 \\
\hline 6 & 15.693 & 3-Buten-2-One, 4-(2-Bromophenyi)- & $\mathrm{C}_{2} \mathrm{H}_{\mathrm{O}} \mathrm{BNONO}$ & 224 & 189 \\
\hline 7 & 16.868 & Tetradecanoic Acid & $\mathrm{C}_{\mathrm{i}} \mathrm{H}_{2 \mathrm{O}} \mathrm{O}_{2}$ & 228 & 0.39 \\
\hline 8 & 18.669 & $\begin{array}{l}\text { Tetradecanoic Acid, 10,13-Dimethyl-; } \\
\text { Methyl Ester }\end{array}$ & $\mathrm{C}_{1} \cdot \mathrm{H}_{3} \mathrm{O}_{2}$ & 270 & 1429 \\
\hline 9 & 22.446 & Hentriacontane & $\mathrm{C}_{22} \mathrm{H}_{34}$ & 436 & 0.56 \\
\hline 10 & 22.896 & $\begin{array}{l}\text { Methanone, ( } 4 \text {-Aminophenyl) } 4 \text { - } \\
\text { Bromophenyl) }\end{array}$ & $\mathrm{C}_{23} \mathrm{H}_{10} \mathrm{BrNO}$ & 275 & 0.84 \\
\hline 11 & 24.256 & $\begin{array}{l}\text { 2,5-Cyclohexadiene-1,4-Dione, } 2,5- \\
\text { Dipbeny! }\end{array}$ & $\mathrm{C}_{10} \mathrm{H}_{\mathrm{L} 2} \mathrm{O}_{2}$ & 260 & 6.59 \\
\hline 12 & 24.491 & Naghthalene, 2-Phenyl- & $\mathrm{C}_{2 n} \mathrm{H}_{\mathrm{Lz}}$ & 204 & 2.49 \\
\hline 13 & 24.947 & $\begin{array}{l}\text { 2-Btomobenzoic Acid, 2,4,5- } \\
\text { Trichloropheny Ester }\end{array}$ & $\mathrm{C}_{5} \mathrm{H}_{3} \mathrm{BrCl}_{5} \mathrm{O}_{2}$ & 378 & 0.83 \\
\hline 14 & 25637 & $\begin{array}{l}\text { Coumanin, 4-[1-(4-Nitropbenyl)-3- } \\
\text { Oxopentylthio]- }\end{array}$ & $\mathrm{C}_{28} \mathrm{H}_{1}-\mathrm{NO}_{5} \mathrm{~S}$ & 383 & 8.73 \\
\hline 15 & 26.202 & $\begin{array}{l}\text { Ergotaman-3,6,18-Trione, 9,10- } \\
\text { Dhiydro- } 12 \text { '-Hydroxy-2'-Methyl-5:- } \\
\text { (Phenylmethyl }\end{array}$ & $\mathrm{C}_{94} \mathrm{H}_{4} \mathrm{~N}_{3} \mathrm{O}_{3} \mathrm{~S}$ & 583 & 0.91 \\
\hline 16 & 27.147 & $\begin{array}{l}\text { Acethydrazide, } 2,2,2-\text { Trifluoto-N2-(4- } \\
\text { Btomobenzoy)- }\end{array}$ & $\mathrm{C}_{3} \mathrm{H}_{3} \mathrm{BrF}_{3} \mathrm{~N}_{2} \mathrm{O}_{2}$ & 310 & 12.36 \\
\hline
\end{tabular}

TABLE 2: Molecular structures, nature and their biological activities of the phytochemical compounds of methanol extracts of Ulothrix flacca showed by GC-MS analysis. 


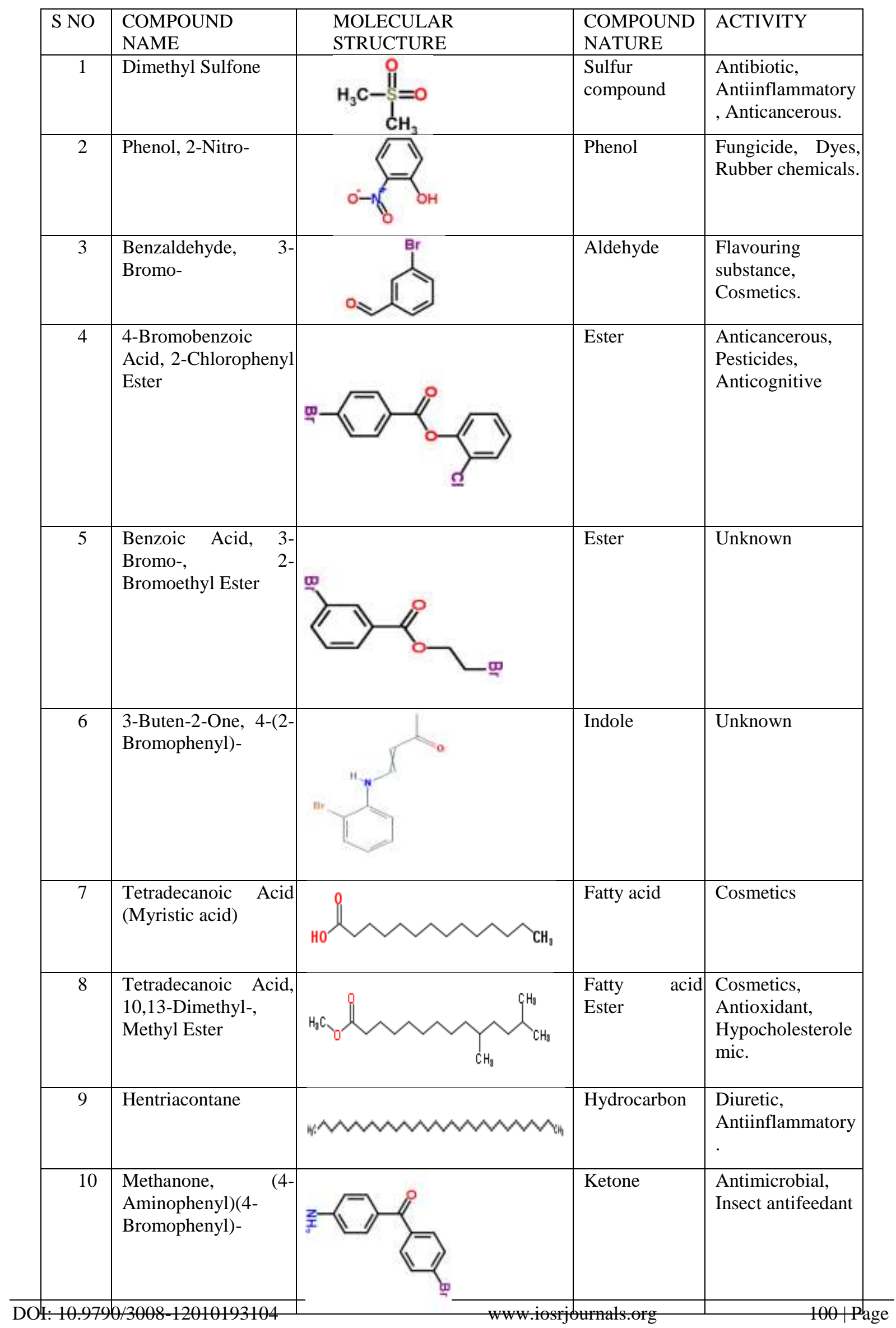




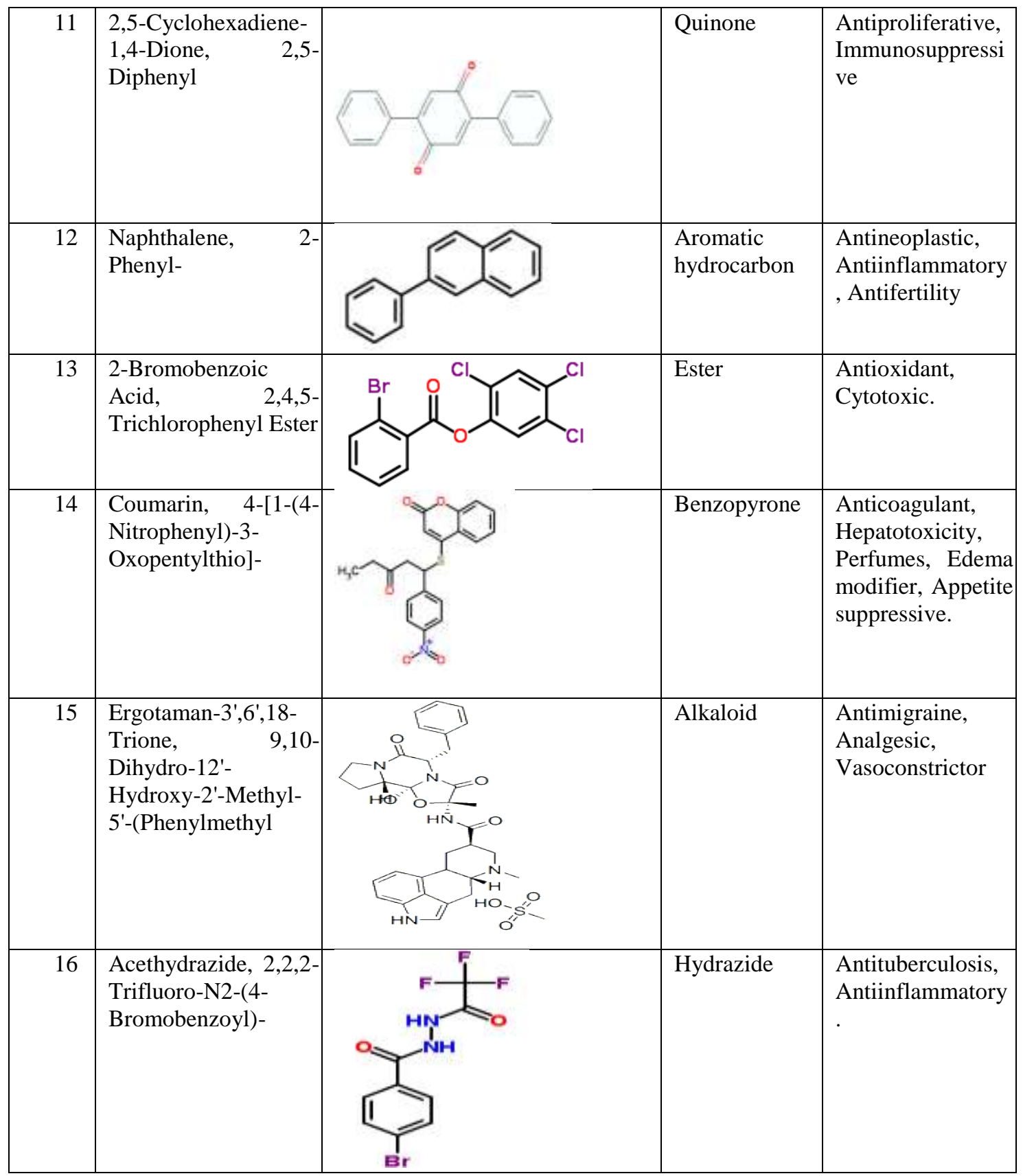

TABLE 3: Total phenols and flavonoids content of Ulothrix flacca methanolic extract.

\begin{tabular}{|l|l|l|}
\hline Methanol extracts & Phenolics \%(w/w) mg GAE/g. & Flavonoids \%(w/w) mg RE/g \\
\hline Ulothrix flacca & $5.74 \pm 0.45$ & $12.58 \pm 1.52$ \\
\hline
\end{tabular}

The values are means \pm SD of three replicates. 
GC/MS analysis and In-vitro Antioxidant activity of methanol extract of Ulothrix flacca and its main ..

TABLE 4: The table represents the reducing potential of methanol extract of Ulothrix flacca and Dimethyl sulfone by DPPH, ABTS, FRAP, PMRP and $\mathrm{Fe}^{2+}$ chelating activities.

\begin{tabular}{|l|l|l|l|l|l|}
\hline $\begin{array}{l}\text { Methanol Extracts } \\
\text { Dimethyl sulfone }\end{array}$ & $\begin{array}{l}\text { DPPH Ic50 } \\
\text { values } \\
(\mathrm{mg} / \mathrm{ml})\end{array}$ & $\begin{array}{l}\text { ABTS } \\
(\mu \mathrm{M} \quad \mathrm{TE} / \mathrm{g} \\
\text { extract) }\end{array}$ & $\begin{array}{l}\text { FRAP } \\
\text { Fe(II)E/mg } \\
\text { extract) }\end{array}$ & $\begin{array}{l}\text { PMRP } \\
\text { AAE/g } \\
\text { extract) }\end{array}$ & $\begin{array}{l}\mathrm{Fe}^{2+} \\
\text { activity } \\
\text { EDTA/g extract) }\end{array}$ \\
\hline $\begin{array}{l}\text { Ulothrix } \\
\text { flacca }\end{array}$ & $9.052 \pm 1.035$ & $10905.6 \pm 159.73$ & $11.577 \pm 1.131$ & $60.66 \pm 7.68$ & $13.155 \pm 0.114$ \\
\hline BHT & $6.35 \pm 1.008$ & $9423.65 \pm 66.82$ & - & -156 \\
\hline Rutin & $9.73 \pm 0.56$ & $8942.79 \pm 119.76$ & $109.28 \pm 5.29$ & $397.18 \pm 5.39$ & - \\
\hline Quercetin & - & - & $287.57 \pm 86.53$ & $457.52 \pm 9.53$ & - \\
\hline EDTA & - & - & - & - & $25.562 \pm 0.895$ \\
\hline
\end{tabular}

Values are mean of triplicate determination $(n=3) \pm$ standard deviation

TE - Trolox Equivalents; AAE - Ascorbic Acid Equivalents; Fe(II)E - Fe(II) Equivalents

Fig 1: GC-MS chromatogram of Ulothrix flacca methanol extract.

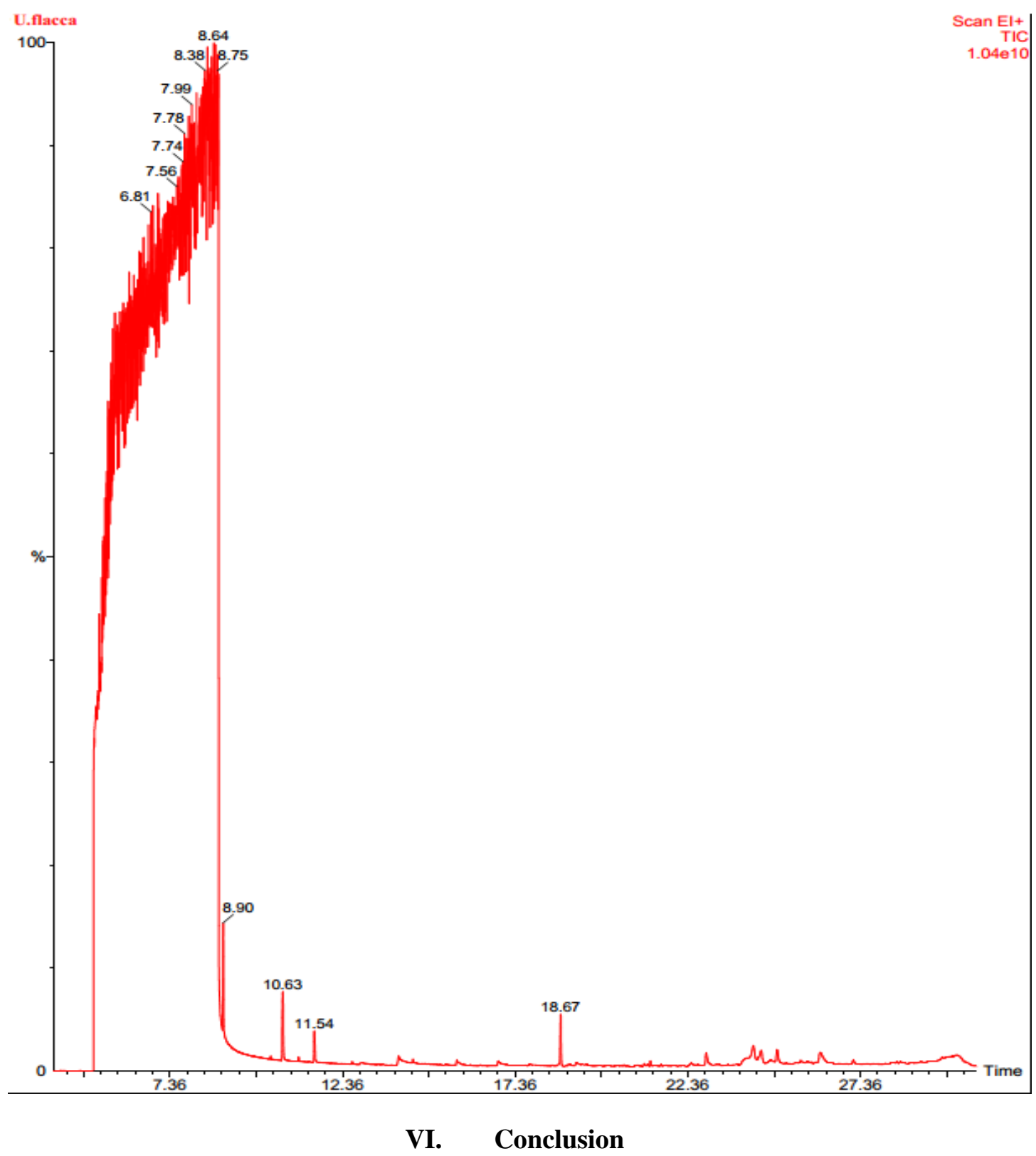

In conclusion, the results of this study suggest that the methanolic extracts of Ulothrix flacca have strong anti-oxidative effects which might be contributed by some major bioactive active compounds such as Dimethyl sulfone, Acethydrazide, 2,2,2-Trifluoro-N2-(4-Bromobenzoyl), Coumarin, 4-[1-(4-Nitrophenyl)-3- 
Oxopentylthio]-, Tetradecanoic Acid, 10,13-Dimethyl-, Methyl Ester, 4-Bromobenzoic Acid, 2-Chlorophenyl Ester and phenol 2-nitro. The anti-oxidative effects of the dimethyl sulfone were better than the methanolic extract which can be used to investigate the in vivo anti-oxidative and anti-cancerous effects in the further studies. Additionally, findings of this study further support the use of the Ulothrix flacca methanol extracts as an anti-oxidative medicine.

\section{Acknowledgements}

The authors wish to thank Dr. Pratap Kumar, Department of Pharmaceutical analysis, MRR college of Pharmacy, JNTUK, Dr. Boominathan, Bharatidasan University, India, for the great support to carry out the work. We also thank Department of Botany, Andhra University for sharing knowledge on seaweeds of Indian coast and to identify them.

\section{References}

[1]. S. SundaraRajan, Introduction to Algae(Anmol Publications PVD.Ltd.,New Delhi, 2001).

[2]. A Mavi, Z. Terzi, U. Ozgen, A. Yildirim andM. Coskun, Antioxidant Properties of Some Medicinal Plants: Prangosferulacea(Apiaceae),Sedum Cruciatataurica (Rubiaceae), Rosa sempervivoides(Crassulaceae),Malvaneglecta (Malvaceae). pimpinellifolia(Rosaceae), Galiumverum subsp. verum (Rubiaceae), Urticadioica (Urticaceae), Biol. Pharm. Bull, 27, 2004, 702-705.

[3]. M Valko, D. Leibfritz, J. Moncol, M.T.D. Cronin, M. Mazur andJ. Telser, Free radicals and antioxidants in normal physiological functions and human disease, Int. J. Biochem. Cell. Biol, 7(1), 2006, 45-78.

[4]. H.H Lee, C.T. Lin andL.L. Yang, Neuroprotection and free radical scavenging effects of Osmanthusfragrans, J Biomed. Sci,14, 2007, 819-827.

[5]. Gulcin,Antioxidant activity of food constituents: an overview, Arch. Toxicol, 86,2012,345-391.

[6]. W Peschel, F. Sanchez-Rabaneda, W. Dieckmann, A. PlescherandI. Gartzia,An industrial approach in the search of natural antioxidants from vegetable and fruits wastes,Food Chem, 97, 2006, 137-150.

[7]. B HalliwellandJ.M.C. Gutteridge,Free Radicals in Biology and Medicine(Oxford University Press, Oxford, 2007).

[8]. K.E Saker, J.H. Fike, H. Veit andD.L. Ward, Brown seaweed- $\left(\right.$ Tasco $\left.^{\mathrm{TM}}\right)$ treated conserved forage enhances antioxidant status and immune function in heat-stressed wether lambs,J. Anim. Physiol. Anim. Nutr, 88(3/4), 2004, 122-130.

[9]. Y Yoshie, W. Wand, Y.P. Hsieh andT. Suzuki, Compositional difference of phenolic compounds between two seaweeds, Halimeda spp,J Tokyo univ Fish, 88, 2002, 21-24.

[10]. S.C Wu, F.J. Wang andC.L. Pan, The comparison of anti-oxidative properties of seaweed oligosaccharides fermented by two lactic acid bacteria, J Mar. Sci. Technol, 18, 2010, 537-545.

[11]. H Türkez, H. Gürbüz, E. Aydin, A. Aslan and E. Dirican,The evaluation of the genotoxic and oxidative damage potentials of Ulothrixtenuissima (Kutz.) in vitro, ToxicolInd Health, 28(2), 2012, 147-151.

[12]. V.L Singleton, R. Orthofer and R.M. Lamuela-Raventos, Analysis of total phenols and other oxidation substrates and antioxidants by means of Folin-Ciocalteu reagent,Methods Enzymol, 299, 1999, 152-178.

[13]. Jiazhishen, Tang Mengcheng and Wu Jianming, The determination of flavonoid contents in mulberry and their scavenging effects on superoxide radicals, Food chemistry, 64, 1999, 555-559.

[14]. A Braca, N.D. Tommasi, L.D. Bari, C. Pizza andM. Politi, I. Morelli, Antioxidant principles from Bauhinia terapotensis,J. Nat. Prod, 64, 2001, 892-895.

[15]. Roberta Re, Nicoletta Pellegrini, Anna Proteggente, AnanthPannala, Min Yang and Catherine Rice-Evans, Antioxidant activity applying an improved ABTS radical cation decolorization assay,Free Radical Biology \& Medicine, 26, 1999, $1231-1237$.

[16]. R Pulido, L. Bravo andF. Sauro-Calixo, Antioxidant activity of dietary polyphenols as determined by a modified ferric reducing/antioxidant power assay, J. Agri. Food chem, 48, 2000, 3396-3402.

[17]. P Prieto, M. Pineda andM. Aguilar, Spectrophotometric quantitation of antioxidant capacity through the formation of a phospho molybdenum complex: specific application to the determination of vitamin E,Analytical Biochemistry, 269, 1999, 337-341.

[18]. T.C.P Dinis, V.M.C. Madeira andM.L.M. Almeida, Action of phenolic derivatives (acetoaminophen, salycilate and 5aminosalycilate) as inhibitors of membrane lipid peroxidation and as peroxyl radical scavengers,Arch. Biochem. Biophys, 315 , 1994, 161-169.

[19]. A.C Silva Ferreira, P. Rodrigues, T. Hogg andD.P. Guedes, Influence of some technological parameters on the formation of dimethyl sulfide, 2-mercaptoethanol, methionol, and dimethyl sulfone in port wines, J Agric Food Chem,51, 2003, 727-732.

[20]. S.E Rose, J.B. Chalk, G.J. Galloway andD.M. Doddrell, Detection of dimethyl sulfone in the human brain by in vivo proton magnetic resonance spectroscopy, MagnReson Imaging, 18, 2000, 95-98.

[21]. U.F Engelke, A. Tangerman, M.A. Willemsen, D. Moskau and S. Loss, Dimethyl sulfone in human cerebrospinal fluid and blood plasma confirmed by one-dimensional $1 \mathrm{H}$ and two dimensional $1 \mathrm{H}-13 \mathrm{C}$ NMR, NMR Biomed,18, 2005, 331-336.

[22]. J.I Morton and B.V. Siegel, Effects of oral dimethyl sulfoxide and dimethyl sulfone on murine autoimmune lymphoproliferative disease, Proc SocExpBiol Med,183, 1986, 227-230.

[23]. K. Horvath, P.E. Noker, S. Somfai-Relle andR. Glavits, I. Financsek, Toxicity of methylsulfonylmethane in rats, Food ChemToxicol,40, 2002, 1459-1462.

[24]. L.S Kim, L.J. Axelrod, P. Howard, N. Buratovich andR.F. Waters, Efficacy of methylsulfonylmethane (MSM) in osteoarthritis pain of the knee: a pilot clinical trial, OsteoArthritis Cartilage, 14, 2006, 286-294.

[25]. E Barrager, A.G. Veltmann, Schauss and R.N. Schiller, A multicentered, open-label trial on the safety and efficacy of methyl sulfonyl methane in the treatment of seasonal allergic rhinitis, J Altern Complement Med,8, 2002, 167-173.

[26]. M.A Beilke, C. Collins-Lech andP.G. Sohnle, Effects of dimethyl sulfoxide on the oxidative function of human neutrophils, $J$ Lab Clin Med,110, 1987, 91-96.

[27]. S.W Jacob and J. Appleton, MSM: The definitive guide, a comprehensive review of the science and therapeutics of methylsulfunylmethane, Topanga, (CA: Freedom Press, 2003)107-121.

[28]. S.J Childs, Dimethyl sulfone $\left(\mathrm{DMSO}_{2}\right)$ in the treatment of interstitial cystitis, (UrolClin North Am 21, 1994) 85-88

[29]. J.M Caron, M. Bannon, L. Rosshirt andJ. Luis, L. Montaegudo, Methyl sulfone induces loss of metastatic properties and reemergence of normal phenotype in a metastatic cloudman S-91 (M3) murine melanoma cell line, PLoS ONE,5(8), 2010, e11788. 
[30]. D.Y Kang, P. Darvin, Y.B. Yoo, Y.H. Joung, N. Sp, H.J. Byun and Y.M. Yang,Methylsulfonylmethane inhibits HER2 expression through STAT5b in breast cancer cells,Int J Oncol, 48(2), 2016, 836-842.

[31]. K Ohkura, K. Iwamoto and H. Terada, Transcellular permeation of nitrophenols through newborn rat skin epidermal cells in monolayer culture, Chem Pharm Bull,38(10), 1990, 2788-2791.

[32]. I Mir, M.T. Siddiqui and A.M. Comrie, Antituberculosis agents. V: Alpha-[5-(5-nitro-2-furyl)-1,3,4-oxadiazol-2ylthio] acethydrazide and related compounds, J Pharm Sci, 80(6), 1991, 548-550.

[33]. A.J Giannini,Biological Foundations of Clinical Psychiatry(Oradell, NJ. Medical Economics Puclishing Co., 1986).

[34]. F.A Juhaimi, K. Ghafoorand M.M. Özcan,Physical and chemical properties, antioxidant activity, total phenol and mineral profile of seeds of seven different date fruit (Phoenix dactylifera L.) varieties,Int J Food SciNutr,63(1), 2012, 84-89.

[35]. M Boukouada, Z. Ghiaba, N. Gourine, I. Bombarda, M. Saidi andM. Yousfi, Chemical composition and antioxidant activity of seed oil of two Algerian date palm cultivars (Phoenix dactylifera),Nat Prod Commun,9(12), 2014, 1777-1780.

[36]. K Chow Ching, "Fatty acids in foods and their health implication" 3th ed, (2008).

[37]. P.P Song, J. Zhao, Z.L. Liu, Y.B. Duan, Y.P. Hou, C.Q. Zhao, M. Wu, M. Wei, N.H. Wang, Y. Lv and Z.J. Han,Evaluation of antifungal activities and structure-activity relationships ofCoumarin Derivatives,Pest ManagSci, 73(1), 2017, 94-101.

[38]. V Thomas, D. Giles, P.M. Guru, A.K. Das and A. Patel,Coumarin Derivatives as Anti-inflammatory and Anticancer Agents,Anticancer Agents Med Chem, 2016, [Epub ahead of print].

[39]. S Singla andP. Piplani,Coumarin derivatives as potential inhibitors of acetyl cholinesterase: Synthesis, molecular docking and biological studies, Bioorg Med Chem, 24(19), 2016, 4587-4599.

[40]. L Ronald, Prior andGuohua Cao, Antioxidant phytochemicals in fruits and vegetables: diet and health implications,Hortscience, 35(4), 2000, 588-592.

[41]. Y. Kumarasamy, M. Byres, P.J. Cox, M. Jaspars, L. Nahar andS.D. Sarker, Screening seeds of some Scottish plants for free-radical scavenging activity, Phytother Res, 21, 2007, 615-621.

[42]. S.M Hasan, M.M. Hossain, A. Faruque, M.E.H. Mazumder, M.S. Rana, R. Akter andM.A. Alam, Comparison of antioxidant potential of different fractions of CommelinabenghalensisLinn. Bang,J. Life. Sci, 20(2), 2008, 9-16.

[43]. M.H. Gordon, The mechanism of antioxidant action in vitro, in B. J. F. Hudson (Ed.,) Food antioxidants,(London: Elsevier Applied Science, 1990) 1-18.

[44]. A.M Aboul-Enein, F.K. El Baz, G.S. El-Baroty, A.M. Youssef andH.H.Abd El-Baky, Antioxidant activity of algal extracts on lipid peroxidation,J. Med. Sci, 3, 2003, 87-98. 